\title{
Safety, efficiency and health-related quality of telephone triage conducted by general practitioners, nurses, or physicians in out- of-hours primary care: a quasi-experimental
} study using the Assessment of Quality in Telephone Triage (AQTT) to assess audiorecorded telephone calls

D. S. Graversen ${ }^{1,2^{*}}$ D, M. B. Christensen ${ }^{1,2}$, A. F. Pedersen ${ }^{1,3}$, A. H. Carlsen ${ }^{1}$, F. Bro ${ }^{1,2}$, H. C. Christensen ${ }^{4,5}$, C. H. Vestergaard ${ }^{1}$ and L. Huibers ${ }^{1}$

\footnotetext{
Abstract

Background: To explore and compare safety, efficiency, and health-related quality of telephone triage in out-ofhours primary care $(\mathrm{OOH}-\mathrm{PC})$ services performed by general practitioners (GPs), nurses using a computerised decision support system (CDSS), or physicians with different medical specialities.

Methods: Natural quasi-experimental cross-sectional study conducted in November and December 2016. We randomly selected 1294 audio-recorded telephone triage calls from two Danish OOH-PC services triaged by GPs ( $n=423)$, nurses using CDSS $(n=430)$, or physicians with different medical specialities $(n=441)$. An assessment panel of 24 physicians used a validated assessment tool (Assessment of Quality in Telephone Triage - AQTT) to assess all telephone triage calls and measured health-related quality, safety, and efficiency of triage.

\footnotetext{
* Correspondence: d.graversen@ph.au.dk

'Research Unit for General Practice, Aarhus, Bartholins Allé 2, 8000 Aarhus C, Denmark

${ }^{2}$ Department of Public Health, Aarhus University, Bartholins Allé 2, 8000

Aarhus C, Denmark

Full list of author information is available at the end of the article
}

(c) The Author(s). 2020 Open Access This article is licensed under a Creative Commons Attribution 4.0 International License, which permits use, sharing, adaptation, distribution and reproduction in any medium or format, as long as you give appropriate credit to the original author(s) and the source, provide a link to the Creative Commons licence, and indicate if changes were made. The images or other third party material in this article are included in the article's Creative Commons licence, unless indicated otherwise in a credit line to the material. If material is not included in the article's Creative Commons licence and your intended use is not permitted by statutory regulation or exceeds the permitted use, you will need to obtain permission directly from the copyright holder. To view a copy of this licence, visit http:/creativecommons.org/licenses/by/4.0/. The Creative Commons Public Domain Dedication waiver (http://creativecommons.org/publicdomain/zero/1.0/) applies to the data made available in this article, unless otherwise stated in a credit line to the data. 
(Continued from previous page)

Results: The relative risk (RR) of poor quality was significantly lower for nurses compared to GPs in four out of ten items regarding identifying and uncovering of problems. For most items, the quality tended to be lowest for physicians with different medical specialities. Compared to calls triaged by GPs (reference), the risk of clinically relevant undertriage was significantly lower for nurses, while physicians with different medical specialties had a similar risk (GP: 7.3\%, nurse: 3.7\%, physician: 6.1\%). The risk of clinically relevant overtriage was significantly higher for nurses (9.1\%) and physicians with different medical specialities (8.2\%) compared to GPs (4.3\%). GPs had significantly shorter calls (mean: 2 min 57 s, SD: 105 s) than nurses (mean: 4 min 44 s, SD: 168 s).

Conclusions: Our explorative study indicated that nurses using CDSS performed better than GPs in telephone triage on a large number of health-related items, had a lower level of clinically relevant undertriage, but were perceived less efficient. Calls triaged by physicians with different medical specialities were perceived less safe and less efficient compared to GPs. Differences in the organisation of telephone triage may influence the distribution of workload in primary and secondary $\mathrm{OOH}$ services. Future research could compare the long-term outcomes following a telephone call to OOH-PC related to safety and efficiency.

Keywords: Triage, Telephone, After-hours care, Out-of-hours, Primary health care, General practitioners, Nurses, Safety, Efficiency, Quality of health care

\section{Background}

The pressure on the out-of-hours $(\mathrm{OOH})$ healthcare services, i.e. $\mathrm{OOH}$ primary care (OOH-PC), emergency departments (EDs), and prehospital emergency medical services (EMS), is increasing in many countries $[1,2]$. Telephone triage plays a pivotal role in managing patient flows and workload [1, 3, 4]. Securing a safe and efficient telephone triage is a challenge as it must balance a minimum of undertriage securing high patient safety, while keeping overtriage at an acceptably low level. Existing $\mathrm{OOH}-\mathrm{PC}$ services vary and use different triage models $[5,6]$, and involvement of general practitioners (GPs) is debated [1, 4, 7]. Many countries experience increasing shortage of GPs [8, 9], and GPs report high selfperceived stress and multiple burnout symptoms [10, 11]. In most countries, telephone triage in $\mathrm{OOH}-\mathrm{PC}$ services is performed by nurses using a computerised decision support system (CDSS) [6]. In Denmark, GPs primarily perform the telephone triage [3].

Previous studies have explored the safety and efficiency of telephone triage in OOH-PC services [12-23]. Some have questioned the safety of telephone triage conducted by nurses [13, 24], especially for high-risk calls [24]. Newer studies suggest nurse triage to be safe [1, 12, 20, 25], and concerns mainly regard efficiency $[1,26]$. However, most previous studies have described only nurse-led telephone triage conducted in study settings using vignettes [17, 18], simulated patients $[13,15,19]$, or review of patient records [20]. This approach has provided little uniformity of outcome measures regarding accuracy of triage, patient safety, and efficiency [16]. Moreover, comparative studies of nurse- and GP-led telephone triage are sparse and mostly describe the quality of telephone triage in daytime $[25,27]$ rather than $\mathrm{OOH}$ [12]. To our knowledge, no existing studies have compared telephone triage by physicians with different specialities. Consequently, comparative studies of the quality of $\mathrm{OOH}$ telephone triage by GPs, nurses, and physician with different specialities in natural settings with real patient calls are needed.

After a reorganisation in 2014, two organisations for $\mathrm{OOH}-\mathrm{PC}$ exist in Denmark alongside, one with nurseled telephone triage using CDSS and physician-led triage, and one with GP-led telephone triage. This situation made it possible to explore the quality of the two $\mathrm{OOH}$ telephone triage models in a natural setting. In this study, we aim to explore and compare the safety, efficiency, and health-related quality of telephone triage at $\mathrm{OOH}-\mathrm{PC}$ services performed by GPs, nurses using CDSS, or physicians with different medical specialities.

\section{Methods \\ Design and setting}

We conducted a natural quasi-experimental study in two OOH-PC services in Denmark. We selected the GPC in the Central Denmark Region using GP-led telephone triage and the medical helpline 1813 (MH-1813) in the Capital Region of Denmark using telephone triage performed by registered nurses with a CDSS and physicians with different medical specialities (see Table 1).

In 1992 a reform introduced large-scale GPCs, with GP specialists performing telephone triage [3]. In the Capital Region of Denmark a reorganisation in January 2014 formed the MH-1813, where nurses answer calls using a CDSS with the option to redirect calls to physicians on duty. All triage nurses are certified as registered nurses indicating a completed 3.5-year professional bachelor's degree and completed a 6-week introductory course when employed in MH-1813, and MH-1813 conducts regular audits of nurse calls. Besides answering the redirected calls from nurses, physicians answer 
Table 1 Description of the $\mathrm{OOH}$ organisations in two included telephone triage models

\begin{tabular}{lll}
\hline & GP cooperative (GPC) & Medical helpline 1813 (MH-1813) \\
\hline Region & Central Denmark Region & Capital Region of Denmark \\
Population & $1.2 \mathrm{~m}$ citizens [28] & $1.8 \mathrm{~m}$ citizens [29] \\
Telephone calls in $\mathbf{2 0 1 4}[30]$ & 697,000 & 911,000 \\
Organiser & GPs in the region & Regional administration \\
Organisation and services & - Telephone triage, home visits, & - Telephone triage and home visits run by MH-1813 \\
& and face-to-face consultations & - Face-to-face consultations are located in hospital \\
& at the GPC & facilities and managed by EDs \\
in the service & \\
Remuneration of professionals & Fee for service & \\
Triage professional & GPs or GP trainees in their final year & Payment by the hour \\
& of speciality; no CDSS available & Nurses who are obliged to use a CDSS and option to \\
& redirect calls to a physician Physicians with different \\
& medical specialities (a minority being GPs)
\end{tabular}

approximately one third of all calls to the MH-1813 directly. Physicians employed at MH-1813 have different medical specialties (e.g. internal medicine, pediatrics, anesthesiology, surgery) and varying experience (including junior physicians), with only a minority being a GP. We refer to this group as physicians in the rest of the article. The CDSS is also accessible for physicians, without an obligation to use it [Personal communication with MH-1813] [31]. The GPC and the MH-1813 are open outside office hours, i.e. on weekdays from $4 \mathrm{pm}$ to $8 \mathrm{am}$, weekends all day, and national holidays, offering telephone consultations, clinic consultations and home visits. The $\mathrm{MH}-1813$ is accessible $24 \mathrm{~h} /$ per day, but only calls outside office hours were included to match the GPC opening hours. The OOH-PC services routinely audio-record all calls and have an administrative registration system. We were unable to access patient information on ethnicity, educational level, socio-economic status, or comorbidity.

\section{Selection of calls}

We aimed to include an equal distribution of calls triaged by GPs, nurses, and physicians. For our power calculation, we used the level of undertriage, as this potentially has most clinical implications. Based on literature, we assumed an undertriage rate of approximately $9.5 \%$ for a power calculation, an ability to detect a $5 \%$ difference in undertriage between triage professionals, with a power of 0.8 and an alpha of 0.05 . Thus, 435 calls per group of triage professionals were needed. All calls answered directly by a triage professional at GPC or $\mathrm{MH}-1813$ outside office hours during the inclusion period (MH-1813: 23 November - 8 December 2016, GPC: 23 November - 7 December 2016) were eligible (Fig. 1). For calls redirected by a nurse to a physician at MH-1813, only the part conducted by the nurse was eligible. Based on available registration information, we selected eligible calls (Table 2). From all eligible calls we randomly selected (500 calls per triage professional group, matching the overall distribution on day of week (i.e. weekend/not weekend) and time of day (i.e. day, evening, night) using STATA. We selected 525 GPC calls, as we expected more exclusions due to the lack of a separate direct telephone number for nursing homes. Each selected call had a unique identification number that was used to identify the corresponding audiorecorded call.

Three master students of medicine masked the audio recordings using beep tones to mask triage profession, $\mathrm{OOH}$ organisation, and patient identification information. These medical students were trained and each student was supervised for the first 20 calls by DSG in the masking and exclusion process. If a call fulfilled or if the student was in doubt if the call fulfilled the exclusion criteria. Final decisions to exclude or not were made by first author (DSG), or if in doubt, a consensus was reached between DSG and AFP. Due to an unforeseen partly system failure of the IT system at $\mathrm{MH}-1813$ for 3 days, we were unable to get the audio-recordings of 194 selected calls (22\% of all MH-1813 calls). We substituted these with randomly selected calls from the following week, matching on day of week and time of day.

\section{Assessment tool}

Assessments were performed using the tool "Assessment of Quality in Telephone Triage" (AQTT) and the accompanying rating manual printed in a booklet (Appendices 1 and 2 provides an overview of the 24 items and the general rating scale for most specific items). The AQTT was thoroughly developed and tested, with satisfactory inter-rater agreement when distinguishing poor from sufficient performance [32]. The AQTT comprises 24 items assessing the health-related quality (eleven 


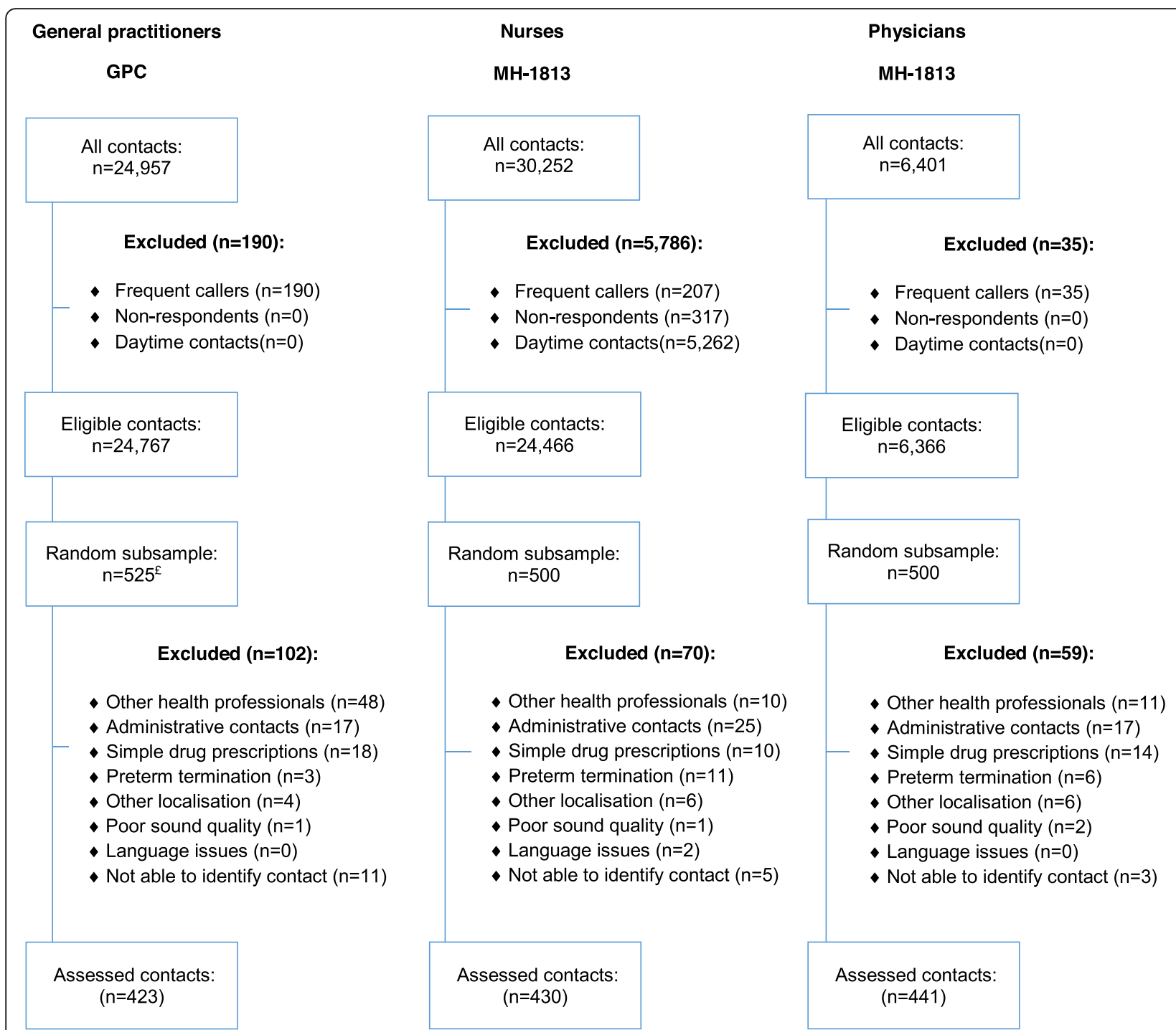

Fig. 1 Flowchart of selection and exclusion of calls from the GPC and MH-1813. Note: For definition of exclusion criteria see Table 2; ${ }^{\mathrm{E}}$ More calls were selected from the GPC, to account for the higher expected number of calls from other health professionals

specific items), quality of communication (nine specific items), as well as four overall items of the assessors' general perception of the quality of communication, healthprofessional quality, patient safety, and efficiency. The majority of items are rated on a 5-point Likert scale with an additional category "not applicable" ("n/a") if an item is correctly found not relevant or available information is insufficient for assessment. The accuracy of the triage decision (item 11) is assessed on a 7-point scale to differentiate between levels of undertriage and overtriage (defined in footnotes of Table 6). The AQTT provides explicit definitions of when to apply the specific ratings for each item, including when to score "n/a". Overall items are measured on a 10-point visual analogue scale, representing the general perception of the assessor, after scoring of all specific items. We present results on the eleven health-related items and three overall items (Table 3).

\section{Assessment panel}

We recruited 24 physicians for the assessment panel among triage professionals from the GPC and $\mathrm{MH}$ 1813 using two inclusion criteria: > 1 year experience and currently active in telephone triage in $\mathrm{OOH}-\mathrm{PC}$. An email invitation was sent to all GPs and physicians by their organisers. Using STATA we randomly selected 16 GPs from the 56 interested GPs at the GPC, matching age and sex distribution. At the MH-1813, we included all eight physicians fulfilling our inclusion criteria from the ten interested physicians. All assessors followed a two-day training course providing knowledge on telephone triage and communication, 
Table 2 Exclusion criteria

\begin{tabular}{|c|c|}
\hline Type & Definition/clarification \\
\hline Frequent callers & $\begin{array}{l}\text { Defined as patients with } \geq 7 \text { calls during the two-week inclusion period (assessment of the triage quality could be } \\
\text { difficult as the patient's medical record from the } \mathrm{OOH} \text { service could include important information on these } \\
\text { patients that was available only to the triage professional and not to the assessor) }\end{array}$ \\
\hline Call by mistake & Calls with no caller answering the triage professional. \\
\hline Daytime calls & Calls performed during daytime (the telephone triage service at $\mathrm{MH}-1813$ was available during daytime) \\
\hline Other health professionals & The caller was another healthcare professional, e.g. from a nursing home \\
\hline Administrative calls & The reason for calling was administrative, e.g. calling to get the number for the acute dentist \\
\hline Simple drug prescriptions & The patient called for renewal of a prescription that required little information sharing \\
\hline Preterm termination & Calls that were ended too early, e.g. calls made by error, no sound on call, or sound interrupted in the middle of call \\
\hline Other localisation & $\begin{array}{l}\text { Calls from a caller who was not in the same location as the patient, e.g. parent on the way to pick up a } \\
\text { sick child from day care }\end{array}$ \\
\hline Poor sound quality & Calls with poor sound quality (making assessment difficult) \\
\hline Language issues & Calls in which language issues challenged the triage, i.e. caller did not speak Danish or English \\
\hline Not able to identify call & $\begin{array}{l}\text { Random calls where an exact linkage to the corresponding audio-recorded call or the audio recording } \\
\text { could not be established }\end{array}$ \\
\hline
\end{tabular}

introducing the AQTT and rating manual, and assessing triage calls individually and in plenary, focusing on achieving consistency.

\section{Assessment process}

After collection, we renamed all audio-recorded calls and distributed them at random to the assessment panel, regardless of $\mathrm{OOH}$ service, with one assessor per call. Thus, each assessor assessed calls by all triage professionals. Information on age and sex of the patient, day of week, and the time of each call was available. Assessors made their assessments at home; each assessed a median of 53 (range: 48 to 61) calls during a median period of 111 days.

\section{Statistical analyses}

For health-related specific items, we categorized the outcomes into poor quality (rated "1" or "2") and sufficient quality (rated "3", "4", or "5"). "Not applicable" ("n/a") was recoded into "missing". Accuracy of triage decision (item 11) was categorised into clinically relevant undertriage (rated " 1 " or " 2 ") and clinically relevant overtriage (rated "6" or "7"). These categorizations were based on the satisfactory inter-rater agreement of the AQTT [32].

Table 3 Overview of specific health- professional items and items assessing overall quality

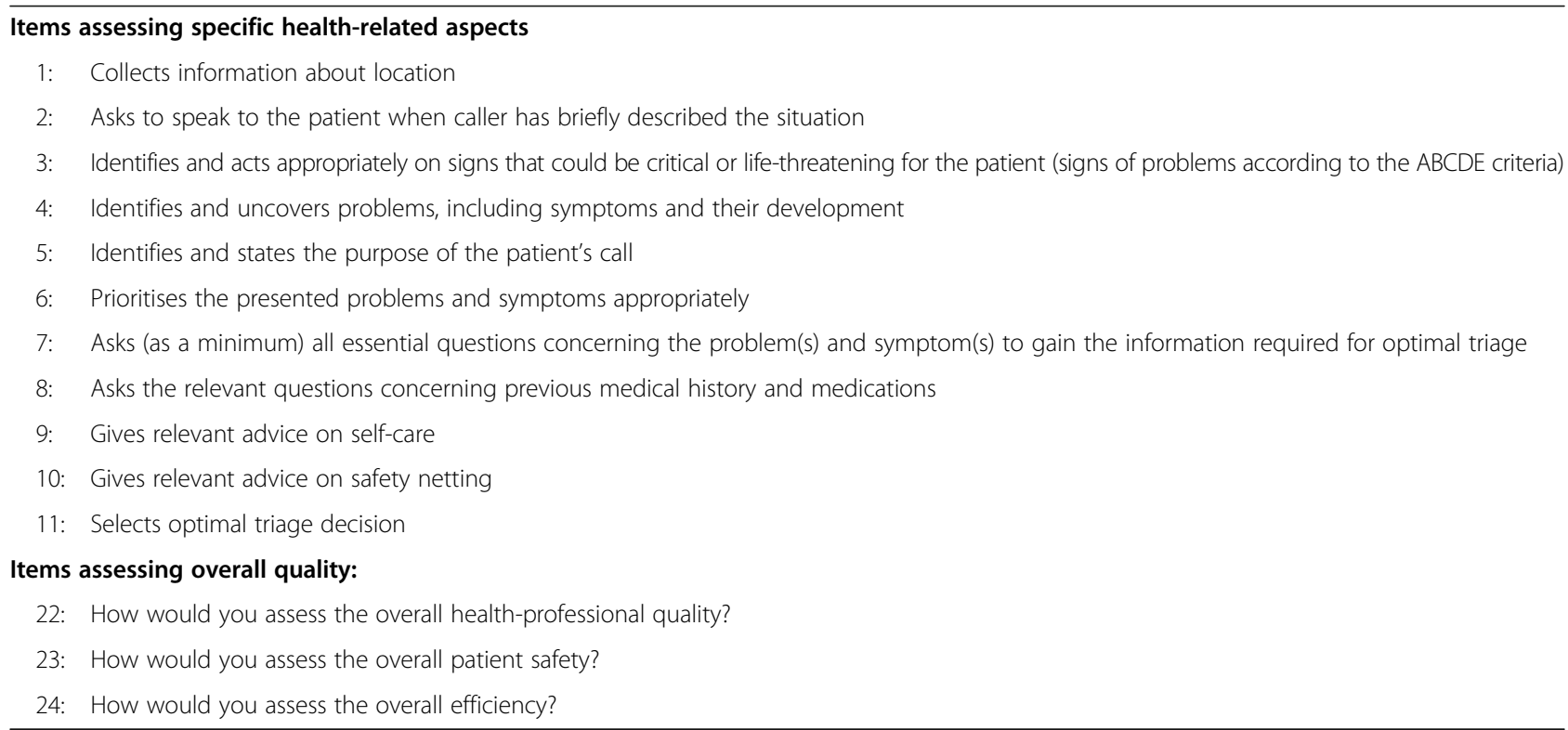


We used descriptive analyses to describe patient and call characteristics stratified by triage professional group. We conducted an overall comparison of patient and call characteristics using chi-square test for categorical variables and Kruskal-Wallis test for continuous variables (significance level $<0.05$ ). In case of a significant difference, we conducted a post-hoc pair-wise comparison using chi-squared test for categorical variables and Mann-Whitney U-test for continuous variables with Bonferroni adjusted significance level $(<0.025)$. We also used descriptive analysis to describe the ordinal-scaled health-related specific items, excluding the rating "n/a" from our analyses. We calculated the relative risk (RR) of having poor quality (i.e. rated "1" or "2") versus sufficient quality (i.e. rated " 3 ", " 4 " or " 5 ") on the healthrelated specific items and of clinically relevant undertriage or overtriage (vs. not clinically relevant undertriage or overtriage) for the three groups of triage professionals, using binomial regression. All comparative analyses were conducted pairwise using GP-led triage as reference group. The items measuring the overall perceived quality were compared by ranksum between triage professional using non-parametric Mann-Whitney U-test as most distributions did not follow normal distribution.

We noticed a tendency to overestimate the quality of GP-led triage for assessors from GPC (i.e. GPs) compared with assessors from $\mathrm{MH}-1813$ as well as the reverse: assessors from $\mathrm{MH}-1813$ overestimating the quality of physician-led triage compared with GP assessors. We concluded that a "similar-to-me" bias was present in the data, i.e. assessors giving a slight bonus to triage led by a similar triage professional to themselves [33]. Since the dataset is unbalanced (GPC: 16 vs. MH1813: 8) and, more importantly, since nurses could never receive such favorable assessment, we decided to adjust the RR estimates of poor quality and of clinically relevant under- and overtriage for whether or not assessor had the same professional background as the triage professional. All analyses were performed in STATA 14.2 (StataCorp. 2015. Stata Statistical Software: Release 14.2. College Station, TX: StataCorp LP).

\section{Results}

\section{Population}

In our final analyses, we included 423 calls triaged by GPs, 430 by nurses, and 441 by physicians of different medical specialties (Fig. 1). No differences in triage calls were identified between GPs and nurses and between GPs and physicians concerning patients' age and sex and time of call (Table 4). An explorative analysis comparing calls of nurses and physicians revealed a significant difference in patients' sex ( $p=0.006$ not shown in table). Nurse telephone calls were significantly longer $($ mean $=$
Table 4 Baseline distribution of patient and call characteristics, stratified by triage professional group

\begin{tabular}{|c|c|c|c|}
\hline $\begin{array}{l}\text { Triage } \\
\text { professional }\end{array}$ & $\mathrm{GP}(\boldsymbol{n}=423)$ & Nurse $(\boldsymbol{n}=430)$ & $\begin{array}{l}\text { Physician } \\
(\boldsymbol{n}=441)\end{array}$ \\
\hline \multicolumn{4}{|c|}{ Patient characteristics } \\
\hline \multicolumn{4}{|c|}{$\operatorname{Sex}, \%(n)^{£}$} \\
\hline Male & $42.8(181)$ & $37.9(163)$ & $47.2(208)$ \\
\hline Female & $57.2(242)$ & $62.1(267)$ & $52.8(233)$ \\
\hline \multicolumn{4}{|c|}{ Age group in years, $\%(n)$} \\
\hline $0-4$ & $20.3(86)$ & $23.6(101)$ & $21.9(96)$ \\
\hline $5-17$ & $15.8(67)$ & $13.3(57)$ & $14.8(65)$ \\
\hline $18-39$ & $29.6(125)$ & $31.5(135)$ & $30.6(134)$ \\
\hline $40-64$ & $21.8(92)$ & $20.6(88)$ & $20.1(88)$ \\
\hline$\geq 65$ & $12.5(53)$ & $11.0(47)$ & $12.6(55)$ \\
\hline
\end{tabular}

\section{Call characteristics}

Time of call ${ }^{\mathrm{a}} \%$ (n)

\begin{tabular}{|c|c|c|c|}
\hline Weekend & $51.6(218)$ & $51.2(220)$ & $50.3(222)$ \\
\hline $\begin{array}{l}\text { Not } \\
\text { weekend }\end{array}$ & $48.5(205)$ & $48.8(210)$ & $49.7(219$ \\
\hline Day & $22.2(94)$ & $22.6(97)$ & $21.1(93)$ \\
\hline Evening & $61.5(260)$ & $60.9(262)$ & $61.5(271)$ \\
\hline Night & $16.3(69)$ & $16.5(71)$ & $17.5(77)$ \\
\hline \multicolumn{4}{|c|}{ gth of call, min and sec $(S D-\sec )^{£}$} \\
\hline lean & $2 \min 57 s(105)^{b}$ & $\begin{array}{l}4 \min 44 \mathrm{~s} \\
(168)^{*}\end{array}$ & $\begin{array}{l}4 \min 1 \mathrm{~s} \\
(146)^{*}\end{array}$ \\
\hline
\end{tabular}

$f$ Indicating a significant difference $(p<0.05)$ between all three groups of triage professionals, using chi-square test for categorical variables and KruskalWallis for length of call

* Significant difference between nurses or physicians in pairwise comparison with GPs as reference group (Bonferroni adjusted $p<0.025$ ), using chi-squared test (all categorical variables) and Mann-Whitney U-test (length of call)

Time of call: Weekend = Friday $4 \mathrm{pm}$ - Sunday midnight; Not weekend $=$ Monday $0 \mathrm{am}$ - Friday $8 \mathrm{am}$; ${ }^{\mathrm{b}}$ Available only for 352 of 423 calls from GPC

4 min $44 \mathrm{~s}$, SD: $168 \mathrm{~s}$ ) compared to calls triaged by GPs $($ mean $=2 \min 57 \mathrm{~s}, \mathrm{SD} 105 \mathrm{~s})$ and physicians $($ mean $=4$ $\min 1 \mathrm{~s}, \mathrm{SD}: 146 \mathrm{~s})$.

\section{Health-related specific items}

Figure 2 shows the distribution of ratings for each group of triage professionals, with varying use of " $n / a$ " between items and between triage professional. For four items the RR of poor quality was significantly lower for nurses compared with GPs: "asks to speak to patient" $(\mathrm{RR}=$ 0.68, 95\% CI: $0.52-0.89)$, "identifies problems" $(R R=$ 0.66 , 95\% CI: 0.52-0.83), "asks essential questions" ( $R R=$ 0.77, 95\% CI: 0.63-0.94), and "asks about medical history" (RR $=0.82,95 \%$ CI: 0.68-0.97) (Table 5). Physicians had a significantly higher RR of a poor quality than GPs for four items (i.e. $6,7,8,9$ ). Table 5 additionally, shows the RR estimates adjusted for evaluator background (GPC, MH-1813) (i.e. similar-to-me) and the uneven constitution of assessors (assessors from GPC:MH-1813 $-16: 8)$. 
1: Collects information about location

2: Asks to speak to the patient

3: Identifies and acts on signs that could be critical

4: Identifies and uncovers problems

5: Identifies the purpose of the patient's contact

6: Prioritises the presented problems and symptoms

7: Asks essential questions required for optimal triage

8: Asks relevantly concerning medical history

9: Advises relevantly on self-care

10: Advises relevantly on safety netting

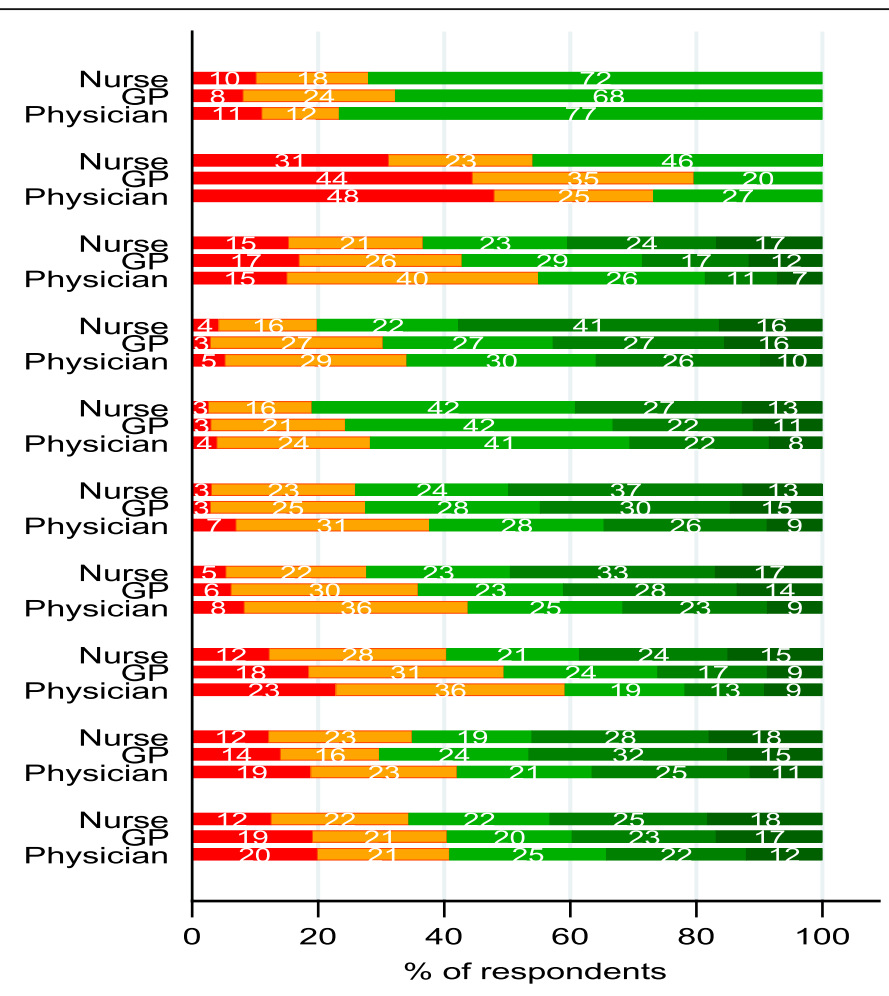

1 Incorrectly left out

2 Insufficient

3 Sufficient

4 Good

Optimal

1: Should have been considered, but was incorrectly omitted, and this could potentially have implications for patient safety or serious negative consequences for the development of the patient's situation

2: Was insufficiently performed, and this could potentially have negative consequences for the development of the patient's situation

3: Was just sufficiently performed, and this did probably not have negative consequences for the development of the patient's situation

4: Was well performed, although there was still room for minor improvements

5: Was optimally performed, with no possibility for improvement

Fig. 2 Distribution of assessments when item was applicable. Note: Distribution of ratings for each specific health-related item. When an item was scored as "not applicable", the call was excluded from the distribution for that particular item. Items 1 and 2: The scale for items 1 and 2 ranges from only one to three, as performance can only be insufficiently performed or performed but with no possibility to excel (thus, "good" or "optimal" performance is not possible). Item headlines in abbreviated form. For full length headlines, see Table 4

\section{Accuracy of triage outcome}

Only $3.7 \%$ of calls triaged by nurses were clinically relevant undertriaged, whereas GPs (7.3\%) and physicians (6.1\%) had higher percentages (Table 6). Consequently, the risk of clinically relevant undertriage was significantly lower for nurses compared to GPs $(R R=0.51$, 95\% CI: 0.28-0.93). Compared to GP-led triage, the risk of being clinically relevant overtriaged was significantly higher for nurse-led ( $R R=2.13,95 \% \mathrm{CI}: 1.22-3.73)$ and physician-led triage $(\mathrm{RR}=1.93,95 \% \mathrm{CI}: 1.10-3.39)$.

\section{Overall perceived quality}

The overall perceived health-professional quality and efficiency of telephone triage was significantly lower for both nurses and physicians compared with GPs (Table 7). The overall perceived patient safety was significantly lower for physicians compared with GPs.

\section{Discussion}

\section{Principal findings}

We found a significant lower risk of poor quality for nurse triage compared to GP triage in four out of ten health-related items that focus on identifying and uncovering the problem and requesting to talk directly to the patient. In four out of ten items, the risk of poor quality was significantly higher in calls triaged by physicians with different medical specialities compared to GPs. The risk of clinically relevant undertriage was significantly 
Table 5 Assessment of percentage poor and relative risk (RR) of poor quality of health-related items for different triage professionals

\begin{tabular}{|c|c|c|c|c|c|}
\hline Health-related specific items (AQTT) & $\begin{array}{l}\text { Triage } \\
\text { professional }\end{array}$ & $\begin{array}{l}\text { Not } \\
\text { applicable } \\
\text { (\%) }\end{array}$ & $\begin{array}{l}\text { Poor quality } \\
\%(n)\end{array}$ & $\begin{array}{l}\text { RR for poor quality }(95 \% \\
\text { Cl) }\end{array}$ & $\begin{array}{l}\text { Adjusted RRC poor quality } \\
(95 \% \mathrm{Cl})\end{array}$ \\
\hline \multirow[t]{3}{*}{ 1: Collects information about location ${ }^{b}$} & GP & 70.7 & $32.3(40)$ & 1 & 1 \\
\hline & Nurse & 60.9 & $28.0(47)$ & $0.87(0.61-1.23)^{P=0.43}$ & $0.91(0.61-1.34)^{P=0.62}$ \\
\hline & Physician & 65.1 & $23.4(36)$ & $0.72(0.49-1.01)^{P=0.10}$ & $0.75(0.51-1.10)^{P=0.142}$ \\
\hline \multirow{3}{*}{$\begin{array}{l}\text { 2: Asks to speak to the patient when the } \\
\text { caller has briefly described the situation }\end{array}$} & GP & 87.2 & $79.6(43)$ & 1 & 1 \\
\hline & Nurse & 85.8 & $54.1(33)$ & $0.68(0.52-0.89)^{* P=0.01}$ & $0.71(0.51-0.98)^{* P=0.04}$ \\
\hline & Physician & 83.9 & $73.2(52)$ & $0.92(0.76-1.12)^{P=0.40}$ & $0.94(0.75-1.17)^{P=0.57}$ \\
\hline \multirow{3}{*}{$\begin{array}{l}\text { 3: Identifies and acts appropriately on signs } \\
\text { that could be critical or life-threatening for } \\
\text { the patient (signs of problems according } \\
\text { to the ABCDE criteria) }\end{array}$} & GP & 73.5 & $42.9(48)$ & 1 & 1 \\
\hline & Nurse & 69.5 & $36.6(48)$ & $0.85(0.63-1.17)^{P=0.32}$ & $0.74(0.55-1.00)^{P=0.05}$ \\
\hline & Physician & 68.3 & $55.0(77)$ & $1.28(0.99-1.67)^{P=0.06}$ & $1.31(1.00-1.70)^{* P=0.05}$ \\
\hline \multirow{3}{*}{$\begin{array}{l}\text { 4: Identifies and uncovers problems, including } \\
\text { symptoms and their development }\end{array}$} & GP & 1.0 & $30.3(127)$ & 1 & 1 \\
\hline & Nurse & 0.5 & $19.9(85)$ & $0.66(0.52-0.83)^{* P=0.00}$ & $0.61(0.47-0.80)^{* P}=0.00$ \\
\hline & Physician & 0.2 & $34.1(150)$ & $1.12(0.93-1.37)^{P=0.24}$ & $1.09(0.89-1.34)^{P=0.39}$ \\
\hline \multirow{3}{*}{$\begin{array}{l}\text { 5: Identifies and states the purpose of } \\
\text { the patient's call }\end{array}$} & GP & 20.3 & $24.3(82)$ & 1 & 1 \\
\hline & Nurse & 19.3 & $19.0(66)$ & $0.78(0.59-1.04)^{P=0.09}$ & $0.76(0.54-1.70)^{P=0.12}$ \\
\hline & Physician & 19.1 & $28.3(101)$ & $1.16(0.91-1.49)^{P=0.24}$ & $1.14(0.86-1.50)^{P=0.37}$ \\
\hline \multirow{3}{*}{$\begin{array}{l}\text { 6: Prioritises the presented problems and } \\
\text { symptoms in an appropriate way }\end{array}$} & GP & 1.2 & $27.5(115)$ & 1 & 1 \\
\hline & Nurse & 0.5 & $25.9(111)$ & $0.94(0.75-1.18)^{P=0.0 .60}$ & $0.81(0.63-1.03)^{P=0.8}$ \\
\hline & Physician & 1.8 & $37.6(163)$ & $1.37(1.12-1.67)^{* P=0.00}$ & $1.28(1.05-1.57)^{* P=0.02}$ \\
\hline \multirow{3}{*}{$\begin{array}{l}\text { 7: Asks, as a minimum, all the essential } \\
\text { questions concerning the problem(s) and } \\
\text { symptom(s) required for optimal triage }\end{array}$} & GP & 0.5 & $35.9(151)$ & 1 & 1 \\
\hline & Nurse & 0.0 & 27.7 (119) & $0.77(0.63-0.94)^{* P=0.01}$ & $0.74(0.59-0.93)^{* P=0.01}$ \\
\hline & Physician & 1.1 & $43.8(191)$ & $1.22(1.03-1.44)^{* P=0.02}$ & $1.20(1.01-1.42)^{* P=0.04}$ \\
\hline \multirow{3}{*}{$\begin{array}{l}\text { 8: Asks the relevant questions concerning } \\
\text { previous medical history and medications }\end{array}$} & GP & 32.2 & $49.5(142)$ & 1 & 1 \\
\hline & Nurse & 24.0 & $40.4(132)$ & $0.82(0.68-0.97)^{* P=0.02}$ & $0.75(0.61-0.91)^{* P=0.00}$ \\
\hline & Physician & 28.3 & $59.2(187)$ & $1.20(1.03-1.39)^{* P=0.02}$ & $1.15(0.98-1.34)^{P=0.09}$ \\
\hline \multirow[t]{3}{*}{ 9: Gives relevant advice on self-care } & GP & 34.0 & $29.8(83)$ & 1 & 1 \\
\hline & Nurse & 52.1 & $35.0(72)$ & $1.17(0.91-1.52)^{P=0.22}$ & $0.93(0.71-1.22)^{P=0.60}$ \\
\hline & Physician & 38.6 & $42.1(114)$ & $1.41(1.13-1.78)^{* P=0.00}$ & $1.30(1.03-1.64)^{* P=}=0.03$ \\
\hline \multirow[t]{3}{*}{ 10: Gives relevant advice on safety netting } & GP & 36.9 & $40.5(108)$ & 1 & 1 \\
\hline & Nurse & 55.4 & $34.4(66)$ & $0.85(0.67-1.08)^{P=0.20}$ & $0.75(0.58-0.97)^{* P=} 0.03$ \\
\hline & Physician & 41.7 & $40.9(105)$ & $1.01(0.82-1.24)^{P=0.93}$ & $0.98(0.79-1.20)^{P=0.81}$ \\
\hline
\end{tabular}

The RR for "poor quality" (i.e. "1" or "2") was analysed using binomial regression model (GP as reference group). *Significant differences: $p<0.05$ ${ }^{a}$ Not applicable was expected in a considerable proportion of cases, in line with the instructions for assessment in the guideline (see methods). We calculated the percentage of calls with "poor quality" (i.e. rated " 1 " or " 2 ") of all calls in which the item was relevant (i.e. "not applicable" excluded). 'Items 1 and 2 were rated from " 1 " to " 3 ";

${ }^{\mathrm{C}} \mathrm{RR}$ of poor quality adjusted for evaluator background (GPC, MH-1813) (i.e. if call is assessed by an assessor with the same professional background and organisation (similar-to-me)) and the uneven constitution of assessors (ratio assessors from GPC:MH-1813 - 16:8)

lower for nurses compared to GPs. However, compared to GPs, both nurses and physicians had significantly more clinically relevant overtriage. In addition, the calls were significantly longer for nurses compared to GPs, and the overall perceived efficiency was significantly higher in GP-led telephone triage compared to nurse-led and physician-led triage. The overall perceived safety was significantly lower in physician-led triage and tended to be higher in nurse-led triage compared to GP-led triage.

\section{Strengths and weaknesses of the study}

To our knowledge, this is the first study to compare the quality of $\mathrm{OOH}$ telephone triage performed by GPs, nurses using CDSS, and physicians in a real-life setting. Major strengths are the use of randomly selected real-life calls as opposed to the constructed setup used in previous studies [18-20, 34, 35] and the assessment of a range of outcome measures. Additional strengths are the study size with 1294 calls and the meticulous assessment process using the 
Table 6 Assessed triage decision and relative risk (RR) of optimal triage, undertriage and overtriage for triage professionals

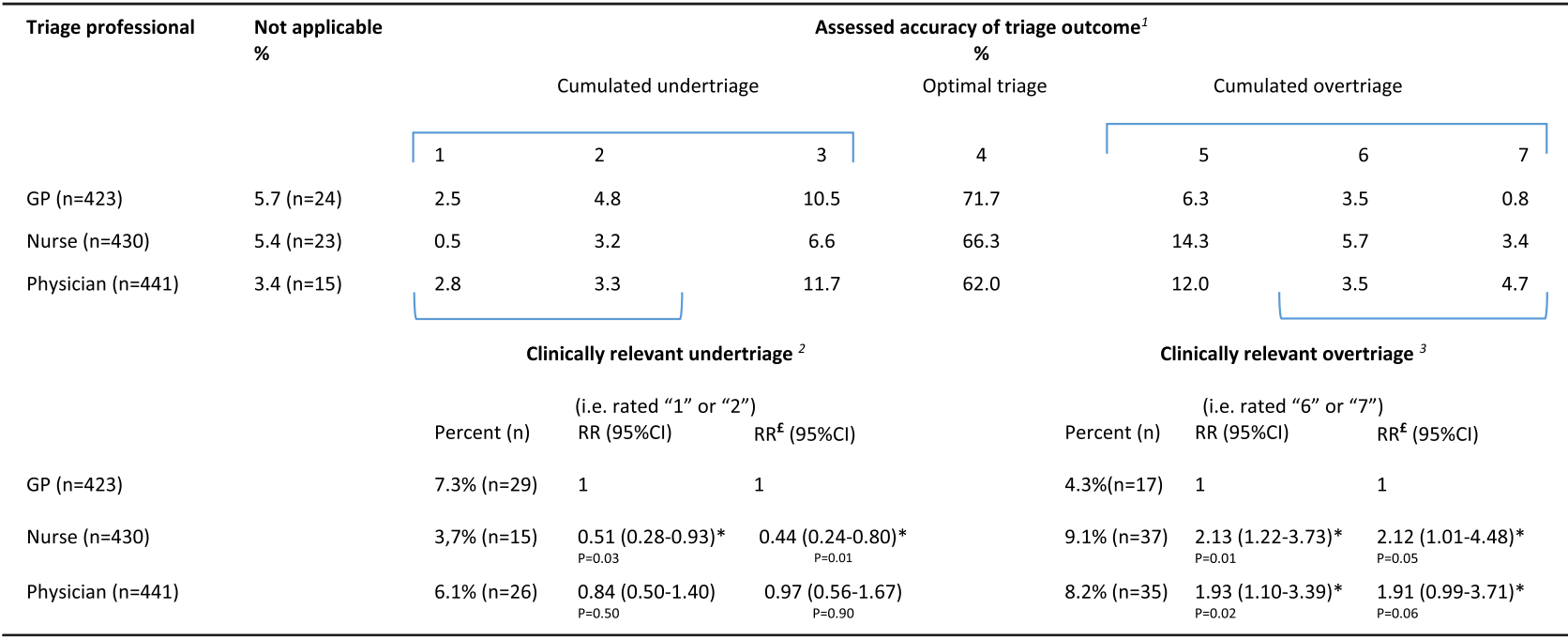

${ }^{1}$ Rating scale assessing appropriateness of triage decision with definitions of each rating: 1. Severe undertriage: The call is undertriaged with risk of severe consequences; 2. Moderate undertriage: The call is undertriaged, but unlikely with risk of severe consequences; 3 . Mild undertriage: The call is undertriaged, but could have been triaged "somewhat higher"; 4 . Optimal triage: The call is optimal triaged; 5 . Mild overtriage: The call is overtriaged, but could have been triaged "somewhat lower"; 6. Moderate overtriage: The call is overtriaged, it would have been sufficient with a "less burdensome service"; 7. Severe overtriage: The call is overtriaged; it seems completely irrelevant to choose this triage outcome

${ }^{2}$ Clinically relevant undertriage is the sum of ratings " 1 " and " 2 "; ${ }^{3}$ Clinically relevant overtriage is the sum of " 6 " and " 7 "; The RR for "clinically relevant undertriage" and clinically relevant overtriage was analysed using binomial regression model. *Significant differences: $p<0.05$

$£$ RR of poor quality adjusted for evaluator background (GPC, MH-1813) (i.e. if call is assessed by an assessor with the same professional background and organisation (similar-to-me)) and the uneven constitution of assessors (ratio assessors from GPC:MH-1813 - 16:8)

validated AQTT tool combined with a comprehensive rating manual that included clear definitions per answering category for each item, thus reducing the subjectivity of the assessments.

Our study also had some limitations. Multiple assessors per call would have been preferable, but due to the thorough assessment process, this was not feasible. Thus, each call was only assessed by a single assessor. We took several precautions to ensure consistency of assessments; the assessors followed a

Table 7 Assessed overall health-related quality, safety, and efficiency per triage professional

\begin{tabular}{|c|c|c|}
\hline $\begin{array}{l}\text { Overall assessed quality } \\
(A Q T T)^{\mathbf{a}}\end{array}$ & $\begin{array}{l}\text { Triage } \\
\text { professional }\end{array}$ & $\begin{array}{l}\text { Median (10th 90th } \\
\text { percentile) }\end{array}$ \\
\hline \multirow{3}{*}{$\begin{array}{l}\text { 22: How would you rate the } \\
\text { overall health-professional } \\
\text { quality in the telephone } \\
\text { triage? }\end{array}$} & GP & $7(3$ to 10$)$ \\
\hline & Nurse & $6(2 \text { to } 9)^{* P}=0.00$ \\
\hline & Physician & $6(2 \text { to } 9)^{* * P}=0.00$ \\
\hline \multirow{3}{*}{$\begin{array}{l}\text { 23: How would you rate the } \\
\text { overall patient safety in the } \\
\text { telephone triage? }\end{array}$} & GP & 8 (3 to 10$)$ \\
\hline & Nurse & $8(3 \text { to } 10)^{P=0.09}$ \\
\hline & Physician & $7(2 \text { to } 10)^{*} P=0.03$ \\
\hline \multirow{3}{*}{$\begin{array}{l}\text { 24: How would you rate } \\
\text { the overall efficiency in the } \\
\text { telephone triage? }\end{array}$} & GP & $8(4$ to 10$)$ \\
\hline & Nurse 1813 & $6(2 \text { to } 9)^{* * P}=0.00$ \\
\hline & Physician 1813 & $7(2 \text { to } 10)^{* * P}=0.00$ \\
\hline
\end{tabular}

Median (10th 90th percentile): Quality was compared to GP-led triage by rank sum using Mann-Whitney U-test. Indicating a significant difference from GP triage, ${ }^{*} p<0.05,{ }^{* *} p<0.001$

a Items were rated on a scale from 0 to $10(0=$ very low quality; $10=$ optimal quality) comprehensive training course, assessments followed the carefully developed and validated AQTT [32], and audio-recordings were attempted masked for information about organisation and triage professional. Moreover, in comparative analyses we dichotomised ratings (distinguishing poor from sufficient quality), which was supported by the satisfactory inter-rater agreement of the AQTT [32].

Post-hoc sensitivity analyses revealed a similar-to-me cognitive bias [33], indicating that the risk of poor quality in calls assessed by an assessor similar to the triage professional tended to be assessed lower than if not assessed by a similar assessor. Furthermore, the decision to include only physicians (GPs from GPC and physicians from $\mathrm{MH}-1813$ ) in the assessment panel may have induced cognitive bias when assessing nurse-led triage. We chose these assessors as no consensus exists on the best professional for assessing quality of telephone triage [13-15, 17, 36], and physicians or GPs have most frequently been used in other studies [13-15]. Moreover, our assessment panel was unbalanced with more assessors from the GPC compared to MH-1813 (16:8). We adjusted for the similar-to-me bias and for the uneven distribution of assessors. The adjusted RR of poor quality and of clinically relevant undertriage and overtriage generally favours nurse triage with lower RR of poor quality. The adjusted RR were comparable to the crude estimates but points towards smaller difference between GPs and physicians for most items. However, the use of non- 
parametric ranksum for the overall perceived quality items did not allow these adjustments. As these items encompass a high level of subjectivity, we assume that adjustment for these factors may have increased differences between the triage professionals.

No differences in calls were seen between the compared groups concerning age, sex, and time of call. We know that populations in the different regions differ, as the percentage of immigrants and the level of education is higher in the Capital Region (MH-1813) [28]. If these differences also exist for callers to the $\mathrm{OOH}$ services, this could potentially give case mix with different levels of difficulty in triage contacts. Moreover, data on other factors like co-morbidity and socioeconomic status were regrettably not available. In addition, some items had considerable proportions of " $\mathrm{n} / \mathrm{a}$ " assessments, as intended, with significant differences between triage professionals in four items. Thus, some case mix cannot be rejected and should be considered especially when interpreting comparisons with small number of calls. Furthermore, we did not have access to background characteristics of the triage professionals, such as age, gender, experience, and education. The management of "n/a" was ambiguous as it could both reflect a correct performance (i.e. "correctly found not relevant"), but could also potentially cover a poor performance (i.e. "available information is insufficient for assessment"). In the testing of the reliability of AQTT "n/a" was recoded into " 3 ", but for the purpose of this paper, we chose to exclude "n/a". Managing " $\mathrm{n} / \mathrm{a}$ " as "sufficient quality" could overestimate the quality. A post-hoc sensitivity analysis of the inter-rater ICC reliability excluding " $\mathrm{n} / \mathrm{a}$ " did not change the reliability considerably, and always towards a higher reliability. In the analyses we have performed many tests so significance by change cannot be excluded. A solution could be adjusting significance levels by Bonferroni consistently throughout all analyses, but this has been suggested to be too conservative and associated with increased risk of type-2 errors [37].

\section{Interpretation and comparisons of results}

Our study revealed that the quality of nurse-led triage using CDSS was higher than GP-led triage for most items and tended to be lower for physicians. However, we cannot say whether these differences are attributed to (non-)use of CDSS, differences in educational background, personality, and/or organisational conditions. CDSSs are developed to support health professionals in asking all essential questions [38] and ensuring consistency [39]. This corresponds to our finding that nurses are better at identifying and uncovering the problems. The differences between physicians and GPs, who did not use CDSS, could suggest that the medical background may be of relevance. The better ability of GPs to prioritise the problems and collect sufficient and complete information compared to physicians with different medical specialities could be attributed to GPs having more experience with similar unvisited patient populations in the daytime.

The rate of cumulated undertriage was $10.3 \%$ for nurses, $17.8 \%$ for GPs, and $17.8 \%$ for physicians, which is in line with other studies of nurse triage in controlled settings (12 to $41 \%)$ [13, 17, 18, 40]. To our knowledge undertriage has not been explored in GP triage. Two large-scale register-based randomised controlled trials comparing GP- and nurse-led telephone triage in daytime [25] and $\mathrm{OOH}$ [12] also suggested that nurse-led triage is safe, finding no excess deaths, hospital admissions, or increased ED attendance attributable to nurseled triage.

Efficient $\mathrm{OOH}$ telephone triage incorporates multiple indicators, including overtriage and length of call. We found that the rate of cumulated overtriage was lowest in GP triage (GP: $11 \%$, nurse: $23 \%$, physician: $20 \%$ ). The overtriage rate in other studies ranges from 12.5 to $19.3 \%$ in nurse-led triage $[13,17,18]$. Telephone calls triaged by nurses were significantly longer than calls triaged by GPs, which is supported by a study [41], but contradicted by another study [42]. The interpretation of the length of a call is ambiguous. A longer call may be more efficient if the problem is sufficiently resolved than a shorter call that does not sufficiently resolve the problem as this may lead to a new contact.

\section{Future research and practical implications}

Our results show that decision-makers should be aware that different triage professionals can cause differences in the quality of telephone triage and may influence the distribution of workload in primary and secondary $\mathrm{OOH}$ services. Nurse-led triage as a solution for high GP workload seems feasible, but further research is needed in this field as fewer GPs are required in telephone triage but more GPs may be needed in face-to-face consultations.

Future research should compare the long-term outcomes following a telephone call to $\mathrm{OOH}$ primary care related to safety (e.g. mortality, hospital admission rates, and adverse events), efficiency (e.g. influence on GP workload, workload in the $\mathrm{OOH}$ services, and follow-up contacts), and patient satisfaction. Additionally, future research should investigate influence of using a CDSS and factors associated with potentially unsafe and inefficient calls, including the characteristics of the triage professional and the type of call.

\section{Conclusion}

Keeping limitations in mind, our explorative study indicated that nurses using CDSS performed better than GPs in telephone triage, especially in four out of ten 
specific health-related items concerning identification and uncovering of the problem. Moreover, nurse-led triage was characterised by a lower level of clinically relevant undertriage, but more clinically relevant overtriage, and was perceived less efficient compared to GP-led triage. Calls triaged by physicians with different medical specialities were perceived less safe and less efficient compared to GPs and tended to receive lowest ratings on most specific items. The use of different triage professionals can influence the quality of telephone triage, and may influence the distribution of workload in primary and secondary $\mathrm{OOH}$ services. Future research could compare the long-term outcomes following a telephone call to $\mathrm{OOH}-\mathrm{PC}$ related to safety and efficiency.

\section{Definitions}

"Health-related quality": the term health-related quality refer to the measured quality in the specific items (used in the red specific items in appendix 1).

"Health-professional quality": the term healthprofessional quality refers to the measured quality exclusively in item 22 assessing the overall perceived healthprofessional quality.

\section{Supplementary information}

Supplementary information accompanies this paper at https://doi.org/10. 1186/s12875-020-01122-z.

Additional file 1: Appendix 1: Assessment tool, AQTT.

Additional file 2: Appendix 2: 5-point Likert rating scale of most specific items in AQTT.

\section{Abbreviations}

AQTT: Assessment of Quality in Telephone Triage (a validated tool for assessment of triage performance); CDSS: Computerised decision support system; ED: Emergency departments; EMS: Emergency medical services; GP: General practitioners; GPC: GP cooperative; $\mathrm{OOH}$ : Out-of-hours; $\mathrm{OOH}$ PC: Out-of-hours primary care

\section{Acknowledgements}

The authors would like to thank the 24 assessors who participated in the assessment process and patients who gave valuable feedback in the development of the AQTT. The authors thank the MH-1813 and GPC organisation for contribution in regards to collection of telephone calls and $\mathrm{MH}-$ 1813 the delivery of manpower.

\section{Authors' contributions}

All authors contributed in the development of the study protocol and design. DSG produced the first draft of the manuscript. DSG, AFP, MB, and $\mathrm{LH}$ contributed to the interpretation of data and critically revised the manuscript. AHC, CHV and DSG contributed with the collection of calls and statistical analyses. FB and HCC contributed with writing of the manuscript. All authors contributed with proofreading of the manuscript. The author(s) read and approved the final manuscript.

\section{Funding}

This study was supported by the Danish foundation TrygFonden, the Foundation for Primary Health Care Research in the Central Denmark Region (Praksisforskningsfonden), the Committee for Quality Improvement and Continuing Medical Education in general practice in the Central Denmark Region (Kvalitets-og Efteruddannelsesudvalget) and the Committee of
Multipractice Studies in General Practice (Multipraksisudvalget). Researchers were independent from funders.

\section{Availability of data and materials}

The anonymised data used and analysed during the current study are available from the corresponding author on reasonable request.

\section{Ethics approval and consent to participate}

The National Committee on Health Research Ethics in the Central Denmark Region was consulted and no approval was required. Danish Patient Safety Authority approved the collection of audio-recorded calls (Reference number: 3-3013-1274/1).

\section{Consent for publication \\ Not applicable.}

\section{Competing interests}

The authors declare that they have no competing interests.

\section{Author details}

${ }^{1}$ Research Unit for General Practice, Aarhus, Bartholins Allé 2, 8000 Aarhus C, Denmark. ${ }^{2}$ Department of Public Health, Aarhus University, Bartholins Allé 2, 8000 Aarhus C, Denmark. ${ }^{3}$ Department of Clinical Medicine, Aarhus University, Aarhus, Denmark. ${ }^{4}$ Emergency Medical Services, Copenhagen, Denmark. ${ }^{5}$ The National Clinical Databases (RKKP), Copenhagen, Denmark.

Received: 1 July 2019 Accepted: 4 March 2020

Published online: 09 May 2020

\section{References}

1. Smits M, Rutten M, Keizer E, Wensing M, Westert G, Giesen P. The development and performance of after-hours primary care in the Netherlands: a narrative review. Ann Intern Med. 2017;166:737-42. https:// doi.org/10.7326/M16-2776.

2. Deloitte. Under pressure The funding of patient care in general practice. 2014. doi:https://www.queensroadpartnership.co.uk/mf.ashx? ID=406a083a144f-457d-b14b-aad537f67fc9.

3. Christensen MB, Olesen F. Out of hours service in Denmark: evaluation five years after reform. Bmj. 1998;316:1502-6.

4. Anderson A, Roland M, lacobucci G. Potential for advice from doctors to reduce the number of patients referred to emergency departments by NHS 111 call handlers: observational study. BMJ. 2015;5:1-4. https://doi.org/10. 1136/bmjopen-2015-009444.

5. Huibers L, Giesen P, Wensing M, Grol R. Out-of-hours care in western countries: assessment of different organizational models. BMC Health Serv Res. 2009;9:1-8. https://doi.org/10.1186/1472-6963-9-105.

6. Berchet $C$, Nader $C$. The organisation of out-of- hours primary care in OECD countries. Paris: OECD Heal Work Pap OECD Publ; 2016. https://doi.org/10. 1787/5j|r3czbqw23-en.

7. Moth G, Huibers L, Vedsted P. From doctor to nurse triage in the Danish out-of-hours primary care service : simulated effects on costs. Int J Fam. 2013;2013:1-6.

8. lacobucci G. GP out-of-hours services struggle to fill shifts amid "intense" winter pressure. Bmj. 2018;97:k97. https://doi.org/10.1136/bmj.k97.

9. The Danish Ministry of Health. En læge tæt på dig [A doctor close to you]. 2018.

10. Nørøxe KB, Pedersen AF, Bro F, Vedsted P. Mental well-being and job satisfaction among general practitioners: a nationwide cross-sectional survey in Denmark. BMC Fam Pract. 2018;19:1-11.

11. Picquendar G, Guedon A, Moulinet F, Schuers M. Influence of medical shortage on GP burnout: a cross-sectional study. Fam Pract. 2018:1-6. https://doi.org/10.1093/fampra/cmy080.

12. Lattimer V, George S, Thompson F, Thomas E, Mullee M, Turnbull J, et al Safety and effectiveness of nurse telephone consultation in out of hours primary care: randomised controlled trial. Bmj. 1998;317:1054-9. https://doi. org/10.1136/bmj.317.7165.1054

13. Giesen P, Ferwerda R, Tijssen R, Mokkink H, Drijver R, van den Bosch W, et al. Safety of telephone triage in general practitioner cooperatives: do triage nurses correctly estimate urgency? Qual Saf Health Care. 2007;16:1814. https://doi.org/10.1136/qshc.2006.018846. 
14. Philips H, Van Bergen J, Huibers L, Colliers A, Bartholomeeusen S, Coenen S, et al. Agreement on urgency assessment between secretaries and general practitioners: an observational study in out-of-hours general practice service in Belgium. Acta Clin Belg. 2015;3286:1-6. https://doi.org/10.1179/ 2295333715 Y.0000000017.

15. Montalto M, Dunt DR, Day SE, Kelaher MA. Testing the safety of after-hours telephone triage: patient simulations with validated scenarios. Australas Emerg Nurs J. 2010;13:7-16. https://doi.org/10.1016/j.aenj.2009.11.003.

16. Bunn F, Byrne G, Kendall S. Telephone consultation and triage: effects on health care use and patient satisfaction. Cochrane Database Syst Rev. 2004. https://doi.org/10.1002/14651858.CD004180.pub2.

17. Hansen EH, Hunskaar S. Telephone triage by nurses in primary care out-ofhours services in Norway: an evaluation study based on written case scenarios. BMJ Qual Saf. 2011;20:390-6.

18. Smits M, Hanssen $S$, Huibers $L$, Giesen P. Telephone triage in general practices: a written case scenario study in the Netherlands. Scand J Prim Health Care. 2016;34:28-36.

19. Huibers L, Giesen P, Smits M, Mokkink H, Grol R, Wensing M. Nurse telephone triage in Dutch out-of-hours primary care: the realtion between history taking and urgency estimation. Eur J Emerg Med. 2012;19:309-15.

20. Smits $M$, Huibers $L$, Kerssemeijer $B$, de Feijter $E$, Wensing $M$, Giesen P. Patient safety in out-of-hours primary care: a review of patient records. BMC Health Serv Res. 2010;10:1-9. https://doi.org/10.1186/1472-6963-10-335.

21. Kempe A, Bunik M, Ellis J, Magid D, Hegarty T, Dickinson LM, et al. How safe is triage by an after-hours telephone call center? Pediatrics. 2006;118:45763. https://doi.org/10.1542/peds.2005-3073.

22. Cullen M, Gardiner L, Asia M, Karabatsos G, Australian M. Universal telenursing triage in Australia and New Zealand. Aust Fam Physician. 2008; 37:476-9.

23. Ng JY, Fatovich DM, Turner VF, Wurmel JA, Skevington SA, Phillips MR. Appropriateness of healthdirect referrals to the emergency department compared with self-referrals and GP referrals. Med J Aust. 2012;197:498-502.

24. Huibers L, Smits M, Renaud V, Giesen P, Wensing M. Safety of telephone triage in out-of-hours care: a systematic review. Scand J Prim Health Care. 2011;29:198-209.

25. Campbell JL, Fletcher E, Britten N, Green C, Holt TA, Lattimer V, et al. Telephone triage for management of same-day consultation requests in general practice (the ESTEEM trial): A cluster-randomised controlled trial and cost-consequence analysis. Lancet. 2014;384:1859-68. https://doi.org/10. 1016/S0140-6736(14)61058-8.

26. Keizer E, Maassen I, Smits M, Wensing M, Giesen P. Reducing the use of out-ofhours primary care services: a survey among Dutch general practitioners. Eur J Gen Pract. 2016;22:189-95. https:/doi.org/10.1080/13814788.2016.1178718.

27. Campbell JL, Fletcher E, Britten N, Green C, Holt T, Lattimer V, et al. The clinical effectiveness and cost-effectiveness of telephone triage for managing same-day consultation requests in general practice: A cluster randomised controlled trial comparing general practitioner-led and nurseled management systems with usual car. Health Technol Assess (Rockv). 2015;19:1-212. https://doi.org/10.3310/hta19130.

28. Statistics Denmark. StatBank Denmark. http://www.statbank.dk/statbank5a/ default.asp?w=1920. Accessed 9 Jan 2019.

29. The Capital Region of Denmark, The Central Denmark Region, The Capital Region of Denmark, The Central Denmark Region. Demographic information. https://www.rm.dk/regional-udvikling/regionen-i-tal/. Accessed 9 Apr 2018.

30. Ebert JF, Huibers L, Lippert FK, Christensen B, Christensen MB. Development and evaluation of an "emergency access button" in Danish out-of-hours primary care: a study protocol of a randomized controlled trial. BMC Health Serv Res. 2017;17:1-8.

31. VIVE. Regionale lægevagter og Akuttelefonen 1813. En kortlægning med fokus på organisering, aktivitet og økonomi [Regional GP Coopratives and Medical Helpline 1813. A mapping focusing on organisation, activity and economi]. 2018.

32. Graversen DS, Pedersen AF, Carlsen AH, Bro F, Huibers L, Christensen MB. Quality of out-of-hours telephone triage by general practitioners and nurses: development and testing of the AQTT - an assessment tool measuring communication, patient safety and efficiency. Scand J Prim Health Care. 2019;37:18-29.

33. Sears GJ, Rowe PM. A personality-based similar-to-me effect in the employment interview: conscientiousness, affect- versus competence- mediated interpretations, and the role of job relevance. Can J Behav Sci. 2003:35:13-24.

34. Hansen EH, Iru L, Ghjuhh WKH, Grfwru S. Monitoring activities in out-ofhours emergency primary care in Norway a special emphasis on nurses telephone triage and counselling monitoring activities in out-of- hours emergency primary care in; 2011.

35. Derkx HP, Rethans J-J, Muijtjens A, Maiburg B, Winkens R, van Rooij H, et al. "Quod scripsi, scripsi." The quality of the report of telephone consultations at Dutch out-of-hours centres. Qual Saf Health Care. 2010;19:e1.

36. Huibers L, Keizer E, Giesen P, Grol R, Wensing M. Nurse telephone triage: good quality associated with appropriate decisions. Fam Pract. 2012;29:547-52

37. Moran MD. Arguments for rejecting the sequential bonferroni in ecological studies. Oikos. 2003;100:403-5.

38. Holmström IK. Decision aid software programs in telenursing: not used as intended? Experiences of Swedish telenurses. Nurs Health Sci. 2007;9:23-8.

39. Murdoch J, Barnes R, Pooler J, Lattimer V, Fletcher E, Campbell JL. The impact of using computer decision-support software in primary care nurseled telephone triage: interactional dilemmas and conversational consequences. Soc Sci Med. 2015;126:36-47. https://doi.org/10.1016/j. socscimed.2014.12.013

40. Derkx HP, Rethans J-JE, Muijtjens AM, Maiburg BH, Winkens R, van Rooij HG, et al. Quality of clinical aspects of call handling at Dutch out of hours centres: cross sectional national study. BMJ. 2008;337:a1264.

41. Mohammed MA, Clements G, Edwards E, Lester H. Factors which influence the length of an out-of-hours telephone consultation in primary care: a retrospective database study. BMC Health Serv Res. 2012;12:430. https://doi. org/10.1186/1472-6963-12-430.

42. Murdoch J, Barnes R, Pooler J, Lattimer V, Fletcher E, Campbell JL. Question design in nurse-led and GP-led telephone triage for same-day appointment requests: a comparative investigation. BMJ Open. 2014;4:1-9. https://doi.org/ 10.1136/bmjopen-2013-004515.

\section{Publisher's Note}

Springer Nature remains neutral with regard to jurisdictional claims in published maps and institutional affiliations.

Ready to submit your research? Choose BMC and benefit from:

- fast, convenient online submission

- thorough peer review by experienced researchers in your field

- rapid publication on acceptance

- support for research data, including large and complex data types

- gold Open Access which fosters wider collaboration and increased citations

- maximum visibility for your research: over 100M website views per year

At BMC, research is always in progress.

Learn more biomedcentral.com/submissions 